\title{
An Extension of the MULTIMOORA Method for Multiple Criteria Group Decision Making Based upon Hesitant Fuzzy Sets
}

\author{
Zhi-Hui Li \\ School of Mathematics, Southwest Jiaotong University, Chengdu, Sichuan 610031, China \\ Correspondence should be addressed to Zhi-Hui Li; lzhmathematics@126.com
}

Received 17 April 2014; Accepted 2 October 2014; Published 12 November 2014

Academic Editor: Ricardo Perera

Copyright ( 2014 Zhi-Hui Li. This is an open access article distributed under the Creative Commons Attribution License, which permits unrestricted use, distribution, and reproduction in any medium, provided the original work is properly cited.

\begin{abstract}
In order to determine the membership of an element to a set owing to ambiguity between a few different values, the hesitant fuzzy set (HFS) has been proposed and widely diffused to deal with vagueness and uncertainty involved in the process of multiple criteria group decision making (MCGDM) problems. In this paper, we develop novel definitions of score function and distance measure for HFSs. Some examples are given to illustrate that the proposed definitions are more reasonable than the traditional ones. Furthermore, our study extends the MULTIMOORA (Multiple Objective Optimization on the basis of Ratio Analysis plus Full Multiplicative Form) method with HFSs. The proposed method thus provides the means for multiple criteria decision making $(\mathrm{MCDM})$ regarding uncertain assessments. Utilization of hesitant fuzzy power aggregation operators also enables facilitating the process of MCGDM. A numerical example of software selection demonstrates the possibilities of application of the proposed method.
\end{abstract}

\section{Introduction}

The fuzzy set (FS) theory, which is a generalization of classical set theory introduced by Zadeh [1], has drawn the attention of many researchers. Several classical extensions such as the interval-valued fuzzy set (IVFS) [2], intuitionistic fuzzy set (IFS) [3-6], interval-valued intuitionistic fuzzy set (IVIFS) [7], linguistic fuzzy set (IFS) [8, 9], type-2 fuzzy set (T-2FS) [10-13], type- $n$ fuzzy set [14], and fuzzy multiset [15] have been developed. In general, many scholars have noticed that the difficulty in establishing the degree of membership of an element in a set does not arise from a margin of error (as in IFS or IVFSs) or a specified possibility distribution of the possible values (as in T-2FSs) but instead originates from our hesitation between a few different values [16]. In fact, it is usually difficult to reach a final agreement during the decision making process when people are hesitant and irresolute for one thing or another. For example, two decision makers (DMs) may differ on the membership degree of an element $x$ to a set $A$ to be assigned, one perhaps wants to assign 0.5 but the other 0.6 and they cannot persuade each other. As such, there is a set of possible values when describing the membership degree of an element. In such cases, the concept of a hesitant fuzzy set (HFS) naturally introduced by Torra and Narukawa [17] and Torra [18] was aimed at dealing with the inherent hesitation in humankind when making a decision. The membership degree of an element to a HFS, called the hesitant fuzzy element (HFE), can be represented by a collection of possible values between 0 and 1 [19]. In this sense, it can provide a relative accurate representation of people's hesitancy when they are describing their preferences over objects, whereas the fuzzy set or its classical extensions cannot handle this situation well. Recently, a great number of other extensions of the HFSs have been developed such as dual hesitant fuzzy sets (DHFSs) [20], interval-valued hesitant fuzzy sets (IVHFS) [21], generalized hesitant fuzzy sets (GHFSs) [22, 23], and hesitant fuzzy linguistic term sets (HFLTSs) $[8,24]$. It is worth noticing that the HFS theory has been applied to many practical problems, especially in the area of decision making $[9,21-28]$.

The main task of multiple criteria group decision making (MCGDM) is to find the most desirable alternative(s) among a set of feasible alternatives based on the preferences provided by a group of decision makers or experts [27, 28]. In recent years, MCGDM with HFSs has attracted a great deal of attention by experts in decision making area 
$[9,23,26-28]$. Xia and $\mathrm{Xu}[25]$ proposed several aggregation operators for hesitant fuzzy information and discussed the relationship between IFS and HFS, based on which they developed some operations and aggregation operators for HFEs. They also illustrated the correlations among the aggregation operators and gave their application in solving decision making problems. Zhang [16] developed a series of hesitant fuzzy power aggregation operators for hesitant fuzzy information, demonstrated several useful properties of the operators and discussed the relationships between them. The new aggregation operators are utilized to develop techniques for MCGDM with hesitant fuzzy information. To differently process and effectively aggregate hesitant fuzzy information and capture their interrelationship Zhou [19] proposed the hesitant fuzzy reducible weighted Bonferroni mean (HFRWBM) and studied some of its prominent characteristics. They further investigated its generalized form, that is, the generalized hesitant fuzzy reducible weighted Bonferroni mean (GHFRWBM). They finally applied the proposed aggregation operators to multicriteria aggregation. Yu et al. [26] investigated aggregation methods for prioritized hesitant fuzzy elements and their application on personnel evaluation. The generalized hesitant fuzzy prioritized weighted average (GHFPWA) and generalized hesitant fuzzy prioritized weighted geometric (GHFPWG) operators are proposed and some desirable properties of the methods are discussed. A procedure and algorithm for MCGDM was provided using GHFPWA or GHFPWG and applied to a representative personnel evaluation problem that involves a prioritization relationship over the evaluation index. Xu and Zhang [28] developed a novel approach based on TOPSIS (Technique for Order Preference by Similarity to Ideal Solution) and the maximizing deviation method for solving multiple criteria decision making (MCDM) problems, in which the evaluation information provided by the decision maker is expressed in HFEs and the information about criterion weights is incomplete.

Based on the MOORA (Multi-Objective Optimization by Ratio Analysis), the MULTIMOORA (Multi-Objective Optimization by Ratio Analysis plus the Full Multiplicative From) method was initially proposed by Brauers and Zavadskas $[29,30]$. In general, the MULTIMOORA is regarded as a supplement for MOORA, which consists of the Ratio System and the Reference Point, with the Full Multiplicative Form. Brauers and Zavadskas [30] applied the MULTIMOORA method in MCDM process. Brauers and Zavadskas [31, 32] discussed the issues of information aggregation and data normalization in MULTIMOORA. The MOORA method has been employed for material selection [33,34]. Brauers and Zavadskas [35] extended MULTIMOORA with triangular fuzzy numbers and Baležentis et al. [36] further proposed fuzzy MULTIMOORA for group decision making. Baležentis and Zeng [37] updated the MULTIMOORA method with T$2 \mathrm{FSs}$, namely, generalized interval-valued trapezoidal fuzzy numbers. Balezentiene et al. [38] offered a MCDM framework for prioritization of energy crops based on fuzzy MULTIMOORA method which enables to tackle uncertain information. Streimikiene and Balezentis [39] applied the MULTIMOORA method for prioritization of the climate change mitigation strategies. Given selection of sustainable energy sources involves some conflicting criteria, Streimikiene et al. [40] employed multicriteria decision methods MULTIMOORA and TOPSIS to facilitate the analysis. In this paper, we propose an improved MULTIMOORA method with HFEs. By ameliorating the definitions of score function and distance measure for HFEs, the proposed method can address the hesitant fuzzy MCGDM problems and therefore reach more accurate decision results. In addition, the comparisons with other methods show the reasonability and efficiency of our algorithms.

The paper proceeds as follows. Section 2 discusses preliminaries for some basic notions, definitions, and properties of PA operator and HFSs. Section 3 presents novel definitions of the score function and the distance measure for HFEs. Section 4 introduces the crisp MULTIMOORA. Section 5 treats the MULTIMOORA method updated with HFEs and puts forward two algorithms for addressing MCGDM problems. Finally, Section 6 presents an application of the proposed methods in group decision making.

\section{Preliminaries}

This section is devoted to introduce some basic notions, definitions, and properties of PA operator and HFSs, which will facilitate our further analysis.

2.1. Power Average Operator. Information aggregation is a process that fuses data from multiple resources by using a proper aggregation technique. As one of the well-known aggregation techniques, the power-average (PA) operator, which is a nonlinear weighted-average aggregation tools whose weighting vectors depend on the input arguments, was initially introduced by Yager [41] and has been receiving extensive attention from researchers and practitioners over the past decades. This subsection aims to briefly introduce the notion of PA operator.

Definition 1 (see [41]). Let $\left(a_{1}, a_{2}, \ldots, a_{n}\right)$ be a collection of crisp numbers; then, a nonlinear weighted-average aggregation tool, which is called PA operator, can be defined as follows:

$$
\begin{aligned}
\operatorname{PA}\left(a_{1}, a_{2}, \ldots, a_{n}\right) & =\frac{\sum_{i=1}^{n}\left(1+T\left(a_{i}\right)\right) a_{i}}{\sum_{i=1}^{n}\left(1+T\left(a_{i}\right)\right)} \\
& =\sum_{i=1}^{n} \frac{1+T\left(a_{i}\right)}{\sum_{i=1}^{n}\left(1+T\left(a_{i}\right)\right)} a_{i},
\end{aligned}
$$

where

$$
T\left(a_{i}\right)=\sum_{j=1, j \neq i}^{n} \sup \left(a_{i}, a_{j}\right),
$$

and $\sup \left(a_{i}, a_{j}\right)$ is the support for $a_{i}$ from $a_{j}$, which satisfies the following properties:
(1) $\sup \left(a_{i}, a_{j}\right) \in[0,1]$;
(2) $\sup \left(a_{i}, a_{j}\right)=\sup \left(a_{j}, a_{i}\right)$;
(3) $\sup \left(a_{i}, a_{j}\right)>\sup \left(a_{s}, a_{t}\right)$, if $\left|a_{i}-a_{j}\right|<\left|a_{s}-a_{t}\right|$. 
Generally, the support (i.e., Sup) measure is recognized as a similarity index. The more the similarity, the closer the two crisp numbers are and the more they support each other. Following Definition 1, the nonlinear weights of the input arguments are $\left(1+T\left(a_{i}\right)\right) / \sum_{i=1}^{n}\left(1+T\left(a_{i}\right)\right)$, $i=1,2, \ldots, n$. If the inherent information of $a_{i}$ is closer to the aggregated information, that is, the support of $a_{i}$ is considerably larger than others, then $a_{i}$ should be assigned more weight. Conversely, if the support of $a_{i}$ is considerably smaller than others, then $a_{i}$ should be assigned less weight. With the aid of the PA operator, the input arguments are allowed to be aggregated to support and reinforce each other. This operator allows for aggregations in which a subset of data clustered around a common value can combine in a nonlinear fashion to a ct in concert in determining the aggregated value. As such, the influence of the input arguments with large deviation will be reduced.

Two useful types of support function are proposed by Yager [41], and they both lie in the unit interval.

Theorem 2 (see [41]). Let $\left(a_{1}, a_{2}, \ldots, a_{n}\right)$ be a collection of crisp numbers, and they will be aggregated by the PA operator. The support functions of the PA operator can be defined as

(1) $\sup \left(a_{i}, a_{j}\right)=K e^{-\alpha\left(a_{i}-a_{j}\right)^{2}}$;

(2) $\sup \left(a_{i}, a_{j}\right)=K\left(1-\left|a_{i}-a_{j}\right|^{\alpha}\right)$,

where $\sup \left(a_{i}, a_{j}\right)$ is the support for $a_{i}$ from $a_{j}$ and $\alpha \geq 0, K \in$ $[0,1]$.

To facilitate further application, this work assumes that $\sup \left(a_{i}, a_{j}\right)=0.5\left(1-\left|a_{i}-a_{j}\right|\right)$ is the calculation form of the support function when the input arguments take the form of crisp numbers.

2.2. Hesitant Fuzzy Sets. In this subsection, we review the basic concepts of hesitant fuzzy sets (HFSs) and hesitant fuzzy elements (HFEs).

Definition 3 (see [18]). A HFS $M$ on $X$ is defined in terms of a function $h_{M}(x)$ when applied to $X$, which returns a finite subset of $[0,1]$; that is,

$$
M=\left\{\left\langle x, h_{M}(x)\right\rangle \mid x \in X\right\},
$$

where $h_{M}(x)$ is a set of some different values in $[0,1]$, representing the possible membership degrees of the element $x \in X$ to $M$.

For convenience, we call $h_{M}(x)$ the hesitant fuzzy element (HFE) and $\mathscr{H}$ the set of all HFEs.

Given three HFEs $h, h_{1}$, and $h_{2}$, Torra and Narukawa [17, 42] defined the following HFE operations.

Definition 4 (see $[17,42])$. Let $h, h_{1}$, and $h_{2}$ be three HFEs defined on $X$; then, we have

(1) $h^{\mathrm{C}}=\bigcup_{\gamma \in h}\{1-\gamma\}$;

(2) $h_{1} \bigcup h_{2}=\bigcup_{\gamma_{1} \in h_{1}, \gamma_{2} \in h_{2}}\left\{\gamma_{1} \vee \gamma_{2}\right\}$;

(3) $h_{1} \cap h_{2}=\bigcup_{\gamma_{1} \in h_{1}, \gamma_{2} \in h_{2}}\left\{\gamma_{1} \wedge \gamma_{2}\right\}$.
To facilitate the aggregation of hesitant fuzzy information, $\mathrm{Xia}$ and $\mathrm{Xu}$ [25] presented the following new operations on HFEs $h, h_{1}$, and $h_{2}$.

Definition 5 (see [25]). Let $h, h_{1}$, and $h_{2}$ be three HFEs defined on $X$; then, we have

(1) $h^{\lambda}=\bigcup_{\gamma \in h}\left\{\gamma^{\lambda}\right\}, \quad \lambda \geq 0$;

(2) $\lambda h=\bigcup_{\gamma \in h}\left\{1-(1-\gamma)^{\lambda}\right\}, \lambda \geq 0$;

(3) $h_{1} \oplus h_{2}=\bigcup_{\gamma_{1} \in h_{1}, \gamma_{2} \in h_{2}}\left\{\gamma_{1}+\gamma_{2}-\gamma_{1} \gamma_{2}\right\}$;

(4) $h_{1} \otimes h_{2}=\bigcup_{\gamma_{1} \in h_{1}, \gamma_{2} \in h_{2}}\left\{\gamma_{1} \gamma_{2}\right\}$.

In order to compare HFEs, the comparison rules for HFEs defined by Xia and $\mathrm{Xu}$ [25] have been widely applied.

Definition 6 (see [25]). Let $h$ be a HFE defined on $X$; then,

$$
s(h)=\frac{\sum_{\gamma \in h} \gamma}{\delta(h)}
$$

is called the score function of $h$, where $\delta(h)$ is the number of elements in $h$. For any two HFEs, $h_{1}$ and $h_{2}$, if $s\left(h_{1}\right)>s\left(h_{2}\right)$, then $h_{1}>h_{2}$; if $s\left(h_{1}\right)=s\left(h_{2}\right)$, then $h_{1}=h_{2}$.

Let $h_{1}$ and $h_{2}$ be two HFEs. In most cases, $\delta\left(h_{1}\right) \neq \delta\left(h_{2}\right)$. To make a comparison of these two HFEs, Xu and Xia [25] extended the shorter HFE until the length of both HFEs was the same, which in fact simply extended the shorter HFE by appending the same value repeatedly. In real application, the appended values reflect the risk preferences of DMs. Optimistic DMs expect desirable outcomes and would append the maximum value, and those with pessimistic anticipate unfavorable results and would append the minimum value [25]. In this paper, we assume that all of the DMs are pessimistic.

Another important concept for HFEs is the distance measure of HFEs and it has been applied to areas such as pattern recognition, cluster analysis, approximate reasoning, image processing, and decision making [8, 9, 21-28, 43, 44]. We first introduce the axiom for distance measure.

Definition 7 (see [27]). Let $h_{1}$ and $h_{2}$ be two HFEs defined on $X$; then, the distance measure between $h_{1}$ and $h_{2}$ is defined as $d\left(h_{1}, h_{2}\right)$, which satisfies the following properties:

(1) $0 \leq d\left(h_{1}, h_{2}\right) \leq 1$;

(2) $d\left(h_{1}, h_{2}\right)=0$ if and only if $h_{1}=h_{2}$;

(3) $d\left(h_{1}, h_{2}\right)=d\left(h_{2}, h_{1}\right)$.

A variety of distance measures of HFEs have been proposed based on Definition 7; two most commonly used of them, which are called hesitant normalized Hamming distance and hesitant normalized Euclidean distance, are introduced as follows. 
Definition 8 (see [16]). Let $h_{1}$ and $h_{2}$ be two HFEs defined on $X$; then,

$$
d_{h n H d}\left(h_{1}, h_{2}\right)=\frac{1}{\delta} \sum_{i=1}^{\delta}\left|h_{1}^{\sigma(i)}-h_{2}^{\sigma(i)}\right|
$$

is defined as the hesitant normalized Hamming distance between $h_{1}$ and $h_{2}$, where $h_{1}^{\sigma(i)}$ and $h_{2}^{\sigma(i)}$ are the ith largest values in $h_{1}$ and $h_{2}$ and $\delta=\max \left\{\delta\left(h_{1}\right), \delta\left(h_{2}\right)\right\}$.

Definition 9 (see [16]). Let $h_{1}$ and $h_{2}$ be two HFEs defined on $X$; then,

$$
d_{h n E d}\left(h_{1}, h_{2}\right)=\left(\frac{1}{\delta} \sum_{i=1}^{\delta}\left|h_{1}^{\sigma(i)}-h_{2}^{\sigma(i)}\right|^{2}\right)^{1 / 2}
$$

is defined as the hesitant normalized Euclidean distance between $h_{1}$ and $h_{2}$, where $h_{1}^{\sigma(i)}$ and $h_{2}^{\sigma(i)}$ are the $i$ th largest values in $h_{1}$ and $h_{2}$ and $\delta=\max \left\{\delta\left(h_{1}\right), \delta\left(h_{2}\right)\right\}$.

2.3. Hesitant Fuzzy Power Average Operators. Generally, the power aggregation operators have been widely diffused to situations in which the input arguments are exact numerical values. Recently, Zhang [16] has extended the power average operator to accommodate hesitant fuzzy information as input.

Definition 10 (see [16]). Let $h_{i}(i=1,2, \ldots, n)$ be a collection of HFEs. If

$$
\operatorname{HFPA}\left(h_{1}, h_{2}, \ldots, h_{n}\right)=\frac{\bigoplus_{i=1}^{n}\left(1+T\left(h_{i}\right)\right) h_{i}}{\sum_{i=1}^{n}\left(1+T\left(h_{i}\right)\right)},
$$

then HFPA is called the hesitant fuzzy power average (HFPA) operator, where

$$
T\left(h_{i}\right)=\sum_{j=1, j \neq i}^{n} \sup \left(h_{i}, h_{j}\right)
$$

and $\sup \left(h_{i}, h_{j}\right)$ is the support for $h_{i}$ from $h_{j}$, which satisfies the following three properties:

(1) $\sup \left(h_{i}, h_{j}\right) \in[0,1]$;

(2) $\sup \left(h_{i}, h_{j}\right)=\sup \left(h_{j}, h_{i}\right)$;

(3) $\sup \left(h_{i}, h_{j}\right)>\sup \left(h_{s}, h_{t}\right)$, if $d\left(h_{i}, h_{j}\right)<d\left(h_{s}, h_{t}\right)$, where $d$ is a distance measure between any two HFEs.

The support measure is essentially a similarity measure. It can be used to measure the proximity of a hesitant fuzzy preference value by one DM to another hesitant fuzzy preference value provided by a different DM. Without loss of generality, the support function for HFEs being used is $\sup \left(h_{i}, h_{j}\right)=1-d\left(h_{i}, h_{j}\right)$ in this study.
Theorem 11 (see [16]). Let $h_{i}(i=1,2, \ldots, n)$ be a collection of HFEs. The aggregated value using the HFPA operator is also a HFE, and

$$
\begin{aligned}
& \operatorname{HFPA}\left(h_{1}, h_{2}, \ldots, h_{n}\right) \\
& =\bigcup_{\gamma_{1} \in h_{1}, \gamma_{2} \in h_{2}, \ldots, \gamma_{n} \in h_{n}}\left\{1-\prod_{i=1}^{n}\left(1-\gamma_{i}\right)^{\left(1+T\left(h_{i}\right)\right) / \sum_{i=1}^{n}\left(1+T\left(h_{i}\right)\right)}\right\} .
\end{aligned}
$$

Definition 12 (see [16]). Let $h_{i}(i=1,2, \ldots, n)$ be a collection of HFEs. A generalized hesitant fuzzy power average (GHFPA) operator is a mapping $H^{n} \rightarrow H$ such that

$$
\operatorname{GHFPA}\left(h_{1}, h_{2}, \ldots, h_{n}\right)=\left(\frac{\bigoplus_{i=1}^{n}\left(1+T\left(h_{i}\right)\right) h_{i}^{\lambda}}{\sum_{i=1}^{n}\left(1+T\left(h_{i}\right)\right)}\right)^{1 / \lambda},
$$

where $T\left(h_{i}\right)$ satisfies conditions (1) to (3) in Definition 7.

Theorem 13 (see [16]). Let $h_{i}(i=1,2, \ldots, n)$ be a collection of HFEs. The aggregated value using the HFPA operator is also a HFE, and

$$
\begin{aligned}
& \operatorname{GHFPA}_{\lambda}\left(h_{1}, h_{2}, \ldots, h_{n}\right) \\
& =\bigcup_{\gamma_{1} \in h_{1}, \gamma_{2} \in h_{2}, \ldots, \gamma_{n} \in h_{n}}\left\{\left(1-\prod_{i=1}^{n}\left(1-\gamma_{i}^{\lambda}\right)^{\left(1+T\left(h_{i}\right)\right) / \sum_{i=1}^{n}\left(1+T\left(h_{i}\right)\right)}\right)^{1 / \lambda}\right\} .
\end{aligned}
$$

Definition 14 (see [16]). Let $h_{i}(i=1,2, \ldots, n)$ be a collection of HFEs. A weighted generalized hesitant fuzzy power average (WGHFPA) operator is a mapping $H^{n} \rightarrow H$ such that

$$
\operatorname{WGHFPA}\left(h_{1}, h_{2}, \ldots, h_{n}\right)=\left(\frac{\bigoplus_{i=1}^{n} w_{i}\left(1+T\left(h_{i}\right)\right) h_{i}^{\lambda}}{\sum_{i=1}^{n} w_{i}\left(1+T\left(h_{i}\right)\right)}\right)^{1 / \lambda},
$$

where

$$
T\left(h_{i}\right)=\sum_{j=1, j \neq i}^{n} w_{j} \operatorname{Sup}\left(h_{i}, h_{j}\right)
$$

with the conditions that $\mathbf{w}=\left(w_{1}, w_{2}, \ldots, w_{n}\right)^{T}, w_{i} \in[0,1]$ for $i=1,2, \ldots, n$, and $\sum_{i=1}^{n} w_{i}=1$.

Theorem 15 (see [16]). Let $h_{i}(i=1,2, \ldots, n)$ be a collection of HFEs. The aggregated value using the HFPA operator is also a HFE, and

$$
\begin{aligned}
& \text { WGHFPA }_{\mathrm{w}, \lambda}\left(h_{1}, h_{2}, \ldots, h_{n}\right) \\
& =\bigcup_{\gamma_{1} \in h_{1}, \gamma_{2} \in h_{2}, \ldots, \gamma_{n} \in h_{n}}\left\{\left(1-\prod_{i=1}^{n}\left(1-\gamma_{i}^{\lambda}\right)^{w_{i}\left(1+T\left(h_{i}\right)\right) / \sum_{i=1}^{n} w_{i}\left(1+T\left(h_{i}\right)\right)}\right)^{1 / \lambda}\right\} .
\end{aligned}
$$




\section{Novel Definitions of the Score Function and the Distance Measure for HFEs}

In this section, we propose novel definitions of the score function and the distance measure for HFEs.

3.1. Score Function for HFEs. In fact, the score function advocated in Definition 6 can be interpreted as the simple arithmetic average of the HFEs if we assume that all the HFEs are of same weights. For a HFS $\left\langle x, h_{E}(x)\right\rangle$, where the HFEs are listed in the set $h=\{0.90,0.85,0.83,0.82,0.10\}$, it is obvious that four out of the five DMs believe the membership degree of $x$ to $M$ is greater than 0.82 , and only one of them recognizes the membership degree as 0.1 . In most cases, we can infer that the membership degree of $x$ to $M$ is probably greater than 0.82 rather than around 0.1 . Therefore, the score function in Definition 6 may be unreasonable in some cases. In what follows, we define a novel definition of the score function of HFSs based on the PA operator.

Definition 16. Let $h$ be a HFE defined on $X$; then, we define

$$
s(h)=\mathrm{PA}(h)
$$

as the score function of $h$, where $\mathrm{PA}(h)$ is the power average of $h$.

The proposed score function can be simply interpreted as the power average of the elements of a HFE. An important characteristic of this score function is that it can reduce the influence caused by the HFE(s) of unduly large (or small) deviation. In another words, if a HFE or some of the HFSs is/are far from most of the others, then it/they will be assigned less weight when aggregated by the PA operator. From this point of view, the score function defined in this study will be more reasonable. In addition, the comparison rules of HFEs are same to that of Definition 6.

Example 17. Suppose that there are two HFEs $h_{1}=\{0.8,0.6$, $0.3,0.2\}$ and $h_{2}=\{0.9,0.4,0.1\}$. According to Definition 6, the scores for $h_{1}$ and $h_{2}$ are, respectively, $s\left(h_{1}\right)=0.4750$ and $s\left(h_{2}\right)=0.46667$. However, if we use the score function in Definition 16 to calculate their scores, we have $T(0.8)=$ 1.2186, $T(0.6)=1.3634, T(0.3)=1.3414$, and $T(0.2)=$ 1.2699 for $h_{1}$, and $T(0.9)=0.6530, T(0.4)=0.8464$, and $T(0.1)=0.7206$ for $h_{2}$, based on which we obtain $s\left(h_{1}\right)=$ 0.4731 and $s\left(h_{2}\right)=0.4595$.

From Example 17, we can know that the weights of each element in $h_{1}$ are 0.25 and the weights of each value in $h_{2}$ are 0.33 according to Definition 6. However, following Definition 16, we obtain that the weights of each element in $h_{1}$ are $0.2413,0.2571,0.2547$, and 0.2469 , respectively, and besides, the weights of each value in $h_{2}$ are $0.3167,0.3537$, and 0.3296 , respectively. Obviously, the elements of unduly large deviation in $h_{1}$, that is, 0.8 and 0.2 , are assigned lower weights if we utilize the proposed score function, which means that the score function defined in this study can alleviate the influence of unduly large (or small) deviations on the aggregation results.
3.2. Distance Measure for HFEs. The hesitant normalized Hamming distance and the hesitant normalized Euclidean distance are widely applied in decision making. However, for two HFEs $h_{1}$ and $h_{2}$, if $\delta\left(h_{1}\right) \neq \delta\left(h_{2}\right)$, the hesitant normalized Hamming distance in Definition 8 and hesitant normalized Euclidean distance in Definition 9 will be somewhat unreasonable because some elements of the shorter HFE are appended subjectively. Hence, this work utilizes a new distance measure defined in the following.

Definition 18. Let $h_{1}$ and $h_{2}$ be two HFEs defined on $X$; then,

$$
d\left(h_{1}, h_{2}\right)=\left|\mathrm{PA}\left(h_{1}\right)-\mathrm{PA}\left(h_{2}\right)\right|
$$

is defined as distance measure between $h_{1}$ and $h_{2}$, where $\mathrm{PA}\left(h_{1}\right)$ and $\mathrm{PA}\left(h_{2}\right)$ are, respectively, the power average of $h_{1}$ and $h_{2}$.

The proof of the fact that the proposed distance measure satisfies the properties in Definition 7 is omitted here because it is trivial. Noteworthy, the proposed distance measure is more objective than those in Definitions 8 and 9 , and it completely incorporates the inherent information of any two HFEs $h_{1}$ and $h_{2}$, which can be illustrated in Example 19.

Example 19. Suppose that there are two HFEs $h_{1}=\{0.8,0.6$, $0.3,0.2\}$ and $h_{2}=\{0.9,0.4,0.1\}$. According to Definitions 7 and 8, the distances between $h_{1}$ and $h_{2}$ are, respectively, $d_{h n H d}\left(h_{1}, h_{2}\right)=0.1500$ and $d_{h n E d}\left(h_{1}, h_{2}\right)=0.0791$. However, if we use the distance measure in Definition 18 to calculate the distance between $h_{1}$ and $h_{2}$, we have $d\left(h_{1}, h_{2}\right)=0.0019$.

Using Definitions 8 and 9 , the distance between $h_{1}$ and $h_{2}$ can only be calculated by extending the $h_{2}$ until the length of $h_{1}$ and $h_{2}$ was the same, which in fact simply extended the $h_{2}$ by appended the minimum value 0.1 . Therefore, these two distances $d_{h n H d}\left(h_{1}, h_{2}\right)$ and $d_{h n E d}\left(h_{1}, h_{2}\right)$ are obtained based on the two HFEs $h_{1}=\{0.8,0.6,0.3,0.2\}$ and $h_{2}^{\prime}=$ $\{0.9,0.4,0.1,0.1\}$, which is subjective to some extent. Whereas the new distance does not need to append values to the shorter HFE until the length of the HFEs are the same, which makes the calculation more objective. In addition, the PA of $h_{1}$ and $h_{2}$ can reduce the influence of unduly large (or small) deviations on the aggregation results, so $\mathrm{PA}\left(h_{1}\right)$ and $\mathrm{PA}\left(h_{2}\right)$ are capable of representing the people's hesitancy more reasonable and more accurate.

\section{The Crisp MULTIMOORA Method}

This section is devoted to briefly introduce the MULTIMOORA (MOORA plus full multiplicative form) method. As already mentioned earlier, Multi-Objective Optimization by Ratio Analysis (MOORA) method was first introduced in [29], and it was then extended to MULTIMOORA because the extension made it more robust. 
Let $X$ be a matrix where its elements $x_{i j}$ denote $i$ th $(i=$ $1,2, \ldots, m)$ alternative of $j$ th $(j=1,2, \ldots, n)$ objective as

$$
\mathbf{X}=\left(x_{i j}\right)_{m \times n}=\left(\begin{array}{cccc}
f_{1} & f_{2} & \cdots & f_{n} \\
x_{11} & x_{12} & \cdots & x_{1 n} \\
x_{21} & x_{22} & \cdots & x_{2 n} \\
\vdots & \vdots & \vdots & \vdots \\
x_{m 1} & x_{m 2} & \cdots & x_{m n}
\end{array}\right) \begin{gathered}
a_{1} \\
a_{2} \\
\vdots \\
a_{m}
\end{gathered}
$$

In general, the criteria comprise benefit type and cost type. If $f_{j}$ is of benefit type, then the greater $x_{i j}$ is the better it will be; if $f_{j}$ is of cost type, then the smaller $x_{i j}$ is the better it will be. MOORA method consists of two parts: the Ratio System and the Reference Point approach. The MULTIMOORA method includes internal normalization and treats originally all the objectives equally important. In principle, all stakeholders interested in the issue only could give more importance to an objective. Therefore they could either multiply the dimensionless number representing the response on an objective with a significance coefficient or they could decide beforehand to split an objective into different subobjectives [29-37, 45].

The Ratio System of MOORA. Ratio system defines data normalization by comparing alternative of an objective to all values of the objective:

$$
x_{i j}^{*}=\frac{x_{i j}}{\sqrt{\sum_{i=1}^{m} x_{i j}^{2}}},
$$

where $x_{i j}^{*}$ denotes $i$ th alternative of $j$ th objective. These numbers usually belong to the interval $[0,1]$; that is, $x_{i j}^{*} \in$ $[0,1](i=1,2, \ldots, m ; j=1,2, \ldots, n)$. The normalized matrix is denoted as $\mathbf{X}^{*}$. These indicators are added (if desirable value of indicator is maximum) or subtracted (if desirable value is minimum). Thus, the summarizing index of each alternative is derived in this way:

$$
y_{i}^{*}=\sum_{j=1}^{g} x_{i j}^{*}-\sum_{j=g+1}^{n} x_{i j}^{*},
$$

where $g=1,2, \ldots, n$ denotes number of objectives to be maximized. Then, every ratio is given the rank: the higher the index $y_{i}^{*}$, the higher the rank.

The Reference Point of MOORA. Reference point approach is based on the Ratio System. The Maximal Objective Reference Point (vector) is found according to ratios found by employing (18). The $j$ th coordinate of the reference point can be described as $r_{j}=\max _{i} x_{i j}^{*}$ in case of maximization. Every coordinate of this vector represents maximum or minimum of certain objective (indicator). Then, every element of normalized response matrix is recalculated and final rank is given according to deviation from the reference point and the Min-Max Metric of Tchebycheff:

$$
\min _{i}\left(\max _{j}\left|r_{j}-x_{i j}^{*}\right|\right) .
$$

The Full Multiplicative Form and MULTIMOORA. Brauers and Zavadskas [29] proposed MOORA to be updated by the Full Multiplicative Form method embodying maximization as well as minimization of purely multiplicative utility function. Overall utility of the $i$ th alternative can be expressed as dimensionless number:

$$
U_{i}^{\prime}=\frac{A_{i}}{B_{i}},
$$

where $A_{i}=\prod_{j=1}^{g} x_{i j}, i=1,2, \ldots, m$ denotes the product of objectives of the $i$ th alternative to be maximized with $g=$ $1,2, \ldots, n$ being the number of objectives to be maximized and where $B_{i}=\prod_{j=g+1}^{n} x_{i j}$ denotes the product of objectives of the $i$ th alternative to be minimized with $n-g$ being the number of objectives (indicators) to be minimized. Thus MULTIMOORA summarizes MOORA (i.e., Ratio System and Reference point) and the Full Multiplicative Form. The Dominance theory was proposed to summarize three ranks provided by respective parts of MULTIMOORA into a single one [35].

\section{MULTIMOORA Based upon HFEs}

The MULTIMOORA method is aimed at helping DMs analyze the problem as part of the decision-making process. In this section, we investigate an MCGDM problem, where the criterion values take the form of HFEs, the weight information on criteria is unknown. First, some notations are used to denote the indices, sets, and variables in an MCGDM problem in the following.

(i) $m$ : Total number of alternatives.

(ii) $n$ : Total number of criteria.

(iii) $s$ : Total number of DMs involved in the decision process.

(iv) $i \in M=\{1,2, \ldots, m\}$ : Index of alternatives.

(v) $j \in N=\{1,2, \ldots, n\}$ : Index of criteria.

(vi) $k \in S=\{1,2, \ldots, s\}$ : Index of DMs.

(vii) $A_{i}$ : The $i$ th alternative.

(viii) $A=\left\{A_{1}, A_{2}, \ldots, A_{m}\right\}$ : A set of $m$ alternatives.

(ix) $C_{j}$ : The $j$ th criterion.

(x) $C=\left\{C_{1}, C_{2}, \ldots, C_{n}\right\}$ : A set of $n$ criteria, which are considered to be independent.

(xi) $D_{k}$ : The $k$ th DM.

(xii) $D=\left\{D_{1}, D_{2}, \ldots, D_{s}\right\}$ : A set of $s$ DMs.

(xiii) $\delta_{k}$ : Weight of the $k$ th DM, where $\sum_{k=1}^{s} \delta_{k}=1,0 \leq$ $\delta_{k} \leq 1$ and $k=1,2, \ldots, s$.

(xiv) $\boldsymbol{\omega}=\left(\omega_{1}, \omega_{2}, \ldots, \omega_{n}\right)^{T}$ : Significant coefficient vector of criteria (which indicates the important degree of each criterion); suppose that $\sum_{j=1}^{n} \omega_{j}=1,0 \leq \omega_{j} \leq 1$, and $j=1,2, \ldots, n$.

(xv) $N_{B}$ : A collection of benefit criteria (i.e., large values of $x_{i j}^{k} s$ indicate great preference). 
(xvi) $N_{C}$ : A collection of cost criteria (i.e., small values of $x_{i j}^{k} s$ indicate great preference) such that $N_{B} \cup N_{C}=N$ and $N_{B} \cap N_{C}=\varnothing$.

(xvii) $h_{i j}^{k}$ : Evaluation on alternative $A_{i}$ concerning criterion $C_{j}$ that is given by decision maker $D_{k}$ and is a HFE.

(xviii) $\mathbf{R}=\left(\mathbf{R}^{1}, \mathbf{R}^{2}, \ldots, \mathbf{R}^{k}\right)^{T}$ : Vector of hesitant fuzzy decision matrices with respect to all DMs.

In this work, we focus on addressing an MCGDM problem aimed at ranking alternatives and selecting the most desirable alternative(s) from a finite set $A$ based on the set $C$. The basic process for solving this MCGDM problem is illustrated in Figure 1. The algorithm involves the following steps.

Algorithm 20. Consider the following.

Step 1. Each DM provides his or her evaluations and constructs his or her own hesitant decision matrix $\mathbf{R}^{k}(k \in S)$ with elements $r_{i j}^{k}\left(i \in M, j \in N_{B}, k \in S\right.$ ) being responses of alternatives.

Step 2. Utilize the HFPA operator (9)

$$
\begin{aligned}
r_{i j} & =\operatorname{HFPA}\left(r_{i j}^{1}, r_{i j}^{2}, \ldots, r_{i j}^{s}\right)=\frac{\bigoplus_{k=1}^{s}\left(1+T\left(r_{i j}^{k}\right)\right) r_{i j}^{k}}{\sum_{k=1}^{s}\left(1+T\left(r_{i j}^{k}\right)\right)} \\
& =\bigcup_{\gamma_{i j}^{(1)} \in h_{i j}^{(1)}, \gamma_{i j}^{(2)} \in h_{i j}^{(2)}, \ldots, \gamma_{i j}^{(s)} \in h_{i j}^{(s)}}\left\{1-\prod_{k=1}^{s}\left(1-\gamma_{i j}^{(k)}\right)^{\left(1+T\left(r_{i j}^{k}\right)\right) / \sum_{k=1}^{s}\left(1+T\left(r_{i j}^{k}\right)\right)}\right\}
\end{aligned}
$$

to aggregate all of the individual hesitant fuzzy decision matrices $\mathbf{R}^{k}=\left(r_{i j}^{k}\right)_{m \times n}(k=1,2, \ldots, s)$ into the collective hesitant fuzzy decision matrix $\mathbf{R}=\left(r_{i j}\right)_{m \times n}$.

Step 3. Because all of the criteria are expressed by the hesitant fuzzy elements, the normalization procedure for the collective hesitant fuzzy decision matrix $\mathbf{R}=\left(r_{i j}\right)_{m \times n}$ is not necessary.

Step 4 (the ratio system). The hesitant fuzzy elements in $\mathbf{R}=$ $\left(r_{i j}\right)_{m \times n}$ are added up for the benefit criteria and subtracted for the cost criteria, which can be represented by $\bigoplus_{j \in N_{B}} r_{i j}$ and $\bigoplus_{j \in N_{C}} r_{i j}$, respectively. Following Definition 16, the scores for $\bigoplus_{j \in N_{B}} r_{i j}$ and $\bigoplus_{j \in N_{C}} r_{i j}$ can be calculated and denoted $s\left(\bigoplus_{j \in N_{B}} r_{i j}\right)$ and $s\left(\oplus_{j \in N_{C}} r_{i j}\right)$, and then we obtain the overall utility of the $i$ th alternative in terms of the Ratio System, which can be represented by

$$
r_{i}=s\left(\bigoplus_{j \in N_{B}} r_{i j}\right)-s\left(\bigoplus_{j \in N_{C}} r_{i j}\right) .
$$

The alternatives are ranked by comparing their overall utility values. Specifically, alternatives with higher overall utility value receive higher ranks.

Step 5 (The Reference Point Approach). The Maximal Objective Reference Vector $(\mathrm{MORV}) \boldsymbol{\varphi}=\left(\varphi_{1}, \varphi_{2}, \ldots, \varphi_{j}, \ldots, \varphi_{n}\right)$ is obtained according to the following two principles: (1) if the criteria are of benefit type, that is, $C_{j}\left(j \in N_{B}\right)$, then $\varphi_{j}=$ $\max _{i \in M}\left\{r_{i j}\right\}, j \in N$; (2) if the criteria are of cost type, that is, $C_{j}\left(j \in N_{C}\right)$, then $\varphi_{j}=\min _{i \in M}\left\{r_{i j}\right\}, j \in N$.

Thereafter, the novel distance measure proposed in Definition 18 can be utilized to identify the collective deviation from the MORV for each alternative:

$$
\mathscr{D}_{i}=\min _{i}\left(\max _{j}\left|\mathrm{PA}\left(r_{i j}\right)-\mathrm{PA}\left(\varphi_{j}\right)\right|\right) \text {. }
$$

Then, the alternatives are ranked in ascending order of $\mathscr{D}_{i}$.

Step 6 (the full multiplicative form). The hesitant fuzzy elements in $\mathbf{R}=\left(r_{i j}\right)_{m \times n}$ are, respectively, multiplied for the benefit criteria and the cost criteria, which can be represented by $\bigotimes_{j \in N_{B}} r_{i j}$ and $\bigotimes_{j \in N_{C}} r_{i j}$, respectively. Following Definition 16, the scores for $\otimes_{j \in N_{B}} r_{i j}$ and $\bigotimes_{j \in N_{C}} r_{i j}$ can be calculated and denoted $s\left(\bigotimes_{j \in N_{B}} r_{i j}\right)$ and $s\left(\bigotimes_{j \in N_{C}} r_{i j}\right)$, and then we obtain the utility of the $i$ th alternative in terms of the Full Multiplicative Form, which can be represented by

$$
U_{i}=\frac{s\left(U_{i}^{+}\right)}{s\left(U_{i}^{-}\right)},
$$

where $U_{i}^{+}=\bigotimes_{j \in N_{B}} r_{i j}(i \in M)$ denotes the product of the criteria of the $i$ th alternative to the maximized with $N_{B}$ being the set of criteria to be maximized, and $U_{i}^{-}=\bigotimes_{j \in N_{C}} r_{i j}(i \in$ $M)$ denotes the product of criteria of the $i$ th alternative to the minimized with $N_{C}$ being the set of criteria to be minimized. The alternatives are ranked in descending order of $U_{i}$.

Step 7. Utilize the Dominance theory [31] to aggregate the three ranks provided by respective parts of MULTIMOORA.

Algorithm 20 is designed for situations in which the information regarding the weights of the DMs and the significant coefficients of the criteria is unknown. For the situations that the information regarding the weights of the DMs and the significant coefficients of the criteria has been obtained, we utilize the WGHFPA operator to aggregate the individual hesitant fuzzy decision matrices and construct Algorithm 21 to deal with these situations.

Algorithm 21. Consider the following.

Step 1. Each DM provides his or her evaluations and constructs his or her own hesitant decision matrix $\mathbf{R}^{k}(k \in S)$ with elements $r_{i j}^{k}\left(i \in M, j \in N_{B}, k \in S\right.$ ) being responses of alternatives.

Step 2. Utilize the WGHFPA operator (12) 


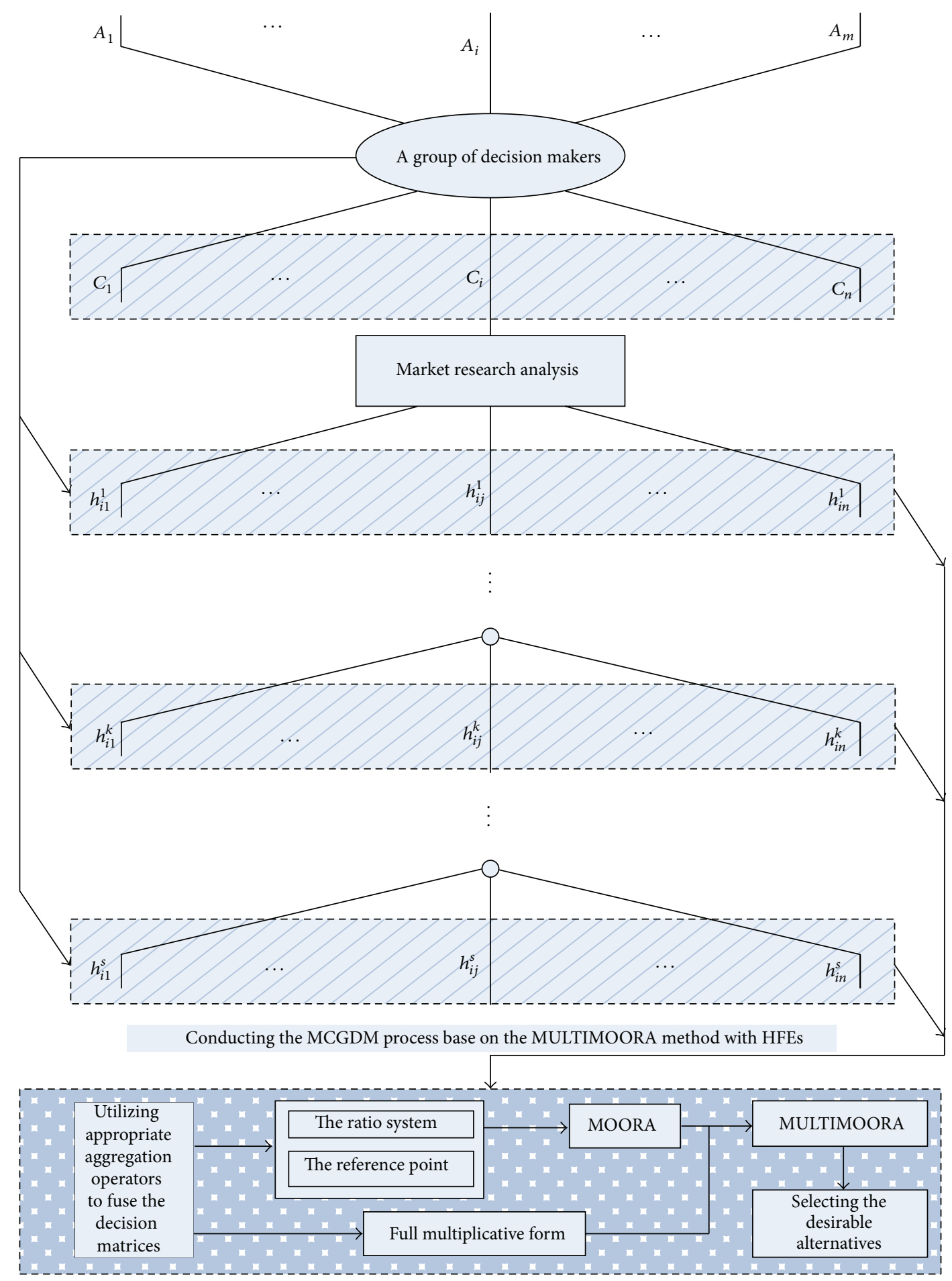

FIGURE 1: The basic process for solving the MCGDM problem. 


$$
\begin{aligned}
r_{i j} & =\operatorname{WGHFPA}\left(r_{i j}^{1}, r_{i j}^{2}, \ldots, r_{i j}^{s}\right)=\left(\frac{\bigoplus_{k=1}^{s} \delta_{k}\left(1+T\left(r_{i j}^{k}\right)\right)\left(r_{i j}^{k}\right)^{\lambda}}{\sum_{k=1}^{s} \delta_{k}\left(1+T\left(r_{i j}^{k}\right)\right)}\right)^{1 / \lambda} \\
& =\bigcup_{\gamma_{i j}^{(1)} \in h_{i j}^{(1)}, \gamma_{i j}^{(2)} \in h_{i j}^{(2)} \ldots, \gamma_{i j}^{(s)} \in h_{i j}^{(s)}}\left\{\left(1-\prod_{k=1}^{s}\left(1-\left(\gamma_{i j}^{(k)}\right)^{\lambda}\right)^{\delta_{k}\left(1+T\left(r_{i j}^{k}\right)\right) / \sum_{k=1}^{s} \delta_{k}\left(1+T\left(r_{i j}^{k}\right)\right)}\right)^{1 / \lambda}\right\}
\end{aligned}
$$

to aggregate all of the individual hesitant fuzzy decision matrices $\mathbf{R}^{k}=\left(r_{i j}^{k}\right)_{m \times n}(k=1,2, \ldots, s)$ into the collective hesitant fuzzy decision matrix $\mathbf{R}=\left(r_{i j}\right)_{m \times n}$.

Step 3. Because all of the criteria are expressed by the hesitant fuzzy elements, the normalization procedure for the collective hesitant fuzzy decision matrix $\mathbf{R}=\left(r_{i j}\right)_{m \times n}$ is not necessary.

Step 4 (the ratio system). The hesitant fuzzy elements in $\mathbf{R}=$ $\left(r_{i j}\right)_{m \times n}$ are added up for the benefit criteria and subtracted for the cost criteria, which can be represented by $\bigoplus_{j \in N_{B}} \omega_{j} r_{i j}$ and $\bigoplus_{j \in N_{C}} \omega_{j} r_{i j}$, respectively. Following Definition 16, the scores for $\bigoplus_{j \in N_{B}} \omega_{j} r_{i j}$ and $\bigoplus_{j \in N_{C}} \omega_{j} r_{i j}$ can be calculated and denoted $s\left(\bigoplus_{j \in N_{B}} \omega_{j} r_{i j}\right)$ and $s\left(\bigoplus_{j \in N_{C}} \omega_{j} r_{i j}\right)$, and then we obtain the overall utility of the $i$ th alternative in terms of the Ratio System, which can be represented by

$$
r_{i}=s\left(\bigoplus_{j \in N_{B}} \omega_{j} r_{i j}\right)-s\left(\bigoplus_{j \in N_{C}} \omega_{j} r_{i j}\right) .
$$

The alternatives are ranked by comparing their overall utility values. Specifically, alternatives with higher overall utility value receive higher ranks.

Step 5 (the reference point approach). The Maximal Objective Reference Vector $(\mathrm{MORV}) \boldsymbol{\varphi}=\left(\varphi_{1}, \varphi_{2}, \ldots, \varphi_{j}, \ldots, \varphi_{n}\right)$ is obtained according to the following two principles: (1) if the criteria are of benefit type, that is, $C_{j}\left(j \in N_{B}\right)$, then $\varphi_{j}=$ $\max _{i \in M}\left\{r_{i j}\right\}, j \in N$; (2) if the criteria are of cost type, that is, $C_{j}\left(j \in N_{C}\right)$, then $\varphi_{j}=\min _{i \in M}\left\{r_{i j}\right\}, j \in N$.

Thereafter, the novel distance measure proposed in Definition 18 can be utilized to identify the collective deviation from the MORV for each alternative:

$$
\mathscr{D}_{i}=\min _{i}\left(\max _{j}\left|\operatorname{PA}\left(\omega_{j} r_{i j}\right)-\operatorname{PA}\left(\omega_{j} \varphi_{j}\right)\right|\right) .
$$

Then, the alternatives are ranked in ascending order of $\mathscr{D}_{i}$.

Step 6 (the full multiplicative form). The hesitant fuzzy elements in $\mathbf{R}=\left(r_{i j}\right)_{m \times n}$ are, respectively, multiplied for the benefit criteria and the cost criteria, which can be represented by $\otimes_{j \in N_{B}} \omega_{j} r_{i j}$ and $\otimes_{j \in N_{C}} \omega_{j} r_{i j}$, respectively. Following Definition 16, the scores for $\otimes_{j \in N_{B}} \omega_{j} r_{i j}$ and $\bigotimes_{j \in N_{C}} \omega_{j} r_{i j}$ can be calculated and denoted $s\left(\bigotimes_{j \in N_{B}} \omega_{j} r_{i j}\right)$ and $s\left(\otimes_{j \in N_{C}} \omega_{j} r_{i j}\right)$, and then we obtain the utility of the $i$ th alternative in terms of the Full Multiplicative Form, which can be represented by

$$
U_{i}=\frac{s\left(U_{i}^{+}\right)}{s\left(U_{i}^{-}\right)}
$$

where $U_{i}^{+}=\bigotimes_{j \in N_{B}} \omega_{j} r_{i j}(i \in M)$ denotes the product of the criteria of the $i$ th alternative to the maximized with $N_{B}$ being the set of criteria to be maximized, and $U_{i}^{-}=\bigotimes_{j \in N_{C}} \omega_{j} r_{i j}(i \epsilon$ $M)$ denotes the product of criteria of the $i$ th alternative to the minimized with $N_{C}$ being the set of criteria to be minimized. The alternatives are ranked in descending order of $U_{i}$.

Step 7. Utilize the Dominance theory [31] to aggregate the three ranks provided by respective parts of MULTIMOORA.

\section{Numerical Example}

In this section, the use of the proposed algorithm is illustrated by the following example.

Wang and Lee [46] considered a software selection problem in which the alternatives are the software packages to be selected and the criteria are the criteria under consideration. Let us reconsider this problem. Suppose that the manager of a computer center at a university wants to select a new information system to improve work productivity. Four alternatives $A_{i}(i=1,2,3,4)$ remain on the candidate list after preliminary screening. Three decision makers $D_{k}(k=$ $1,2,3)$ are chosen from the computer center and form a decision-making committee with the weight vector $\delta=$ $(0.4,0.3,0.3)^{\mathrm{T}}$. The computer center must make a decision according to the following four criteria: (1) the costs of the hardware/software investment $\left(C_{1}\right)$; $(2)$ the contribution to the performance of the organization $\left(C_{2}\right)$; (3) the effort to transfer from the current system $\left(C_{3}\right)$; and (4) the reliability of the outsourcing software developer $\left(C_{4}\right)$. Among the considered criteria, $C_{1}$ is of cost type, and $C_{j}(j=2,3,4)$ are of benefit type. The significant coefficient vector of the criteria $C_{j}(j=1,2,3,4)$ is $\boldsymbol{\omega}=(0.3,0.25,0.25,0.2)^{\mathrm{T}}$.

In this context, the information regarding the weights of the DMs and the significant coefficients of the criteria has been obtained. However, it is common to encounter with situations in which the information regarding the weights of the DMs and the significant coefficients of the criteria is unknown; we first apply Algorithm 20 to support the DMs when making a decision by conducting the following steps. 
TABLE 1: The hesitant fuzzy decision matrix $\mathbf{R}^{1}$ provided by decision maker $D_{1}$.

\begin{tabular}{ccccc}
\hline & $C_{1}$ & $C_{2}$ & $C_{3}$ & $C_{4}$ \\
\hline$A_{1}$ & $\{0.7,0.6,0.5\}$ & $\{0.4,0.3\}$ & $\{0.5,0.4\}$ & $\{0.6\}$ \\
$A_{2}$ & $\{0.6,0.5\}$ & $\{0.4,0.3,0.2\}$ & $\{0.8\}$ & $\{0.7,0.5\}$ \\
$A_{3}$ & $\{0.8\}$ & $\{0.2,0.1\}$ & $\{0.6,0.4,0.3\}$ & $\{0.8,0.7\}$ \\
$A_{4}$ & $\{0.9\}$ & $\{0.9,0.8\}$ & $\{0.7\}$ & $\{0.8,0.7,0.6\}$ \\
\hline
\end{tabular}

TABLE 2: The hesitant fuzzy decision matrix $\mathbf{R}^{2}$ provided by decision maker $D_{2}$.

\begin{tabular}{ccccc}
\hline & $C_{1}$ & $C_{2}$ & $C_{3}$ & $C_{4}$ \\
\hline$A_{1}$ & $\{0.8,0.7,0.6\}$ & $\{0.9,0.7\}$ & $\{0.3,0.2\}$ & $\{0.6,0.5,0.3\}$ \\
$A_{2}$ & $\{0.3\}$ & $\{0.6\}$ & $\{0.7\}$ & $\{0.4,0.3\}$ \\
$A_{3}$ & $\{0.7,0.5\}$ & $\{0.4,0.3\}$ & $\{0.9,0.8,0.7\}$ & $\{0.5,0.4\}$ \\
$A_{4}$ & $\{0.9\}$ & $\{0.5,0.3\}$ & $\{0.5,0.4,0.3\}$ & $\{0.8\}$ \\
\hline
\end{tabular}

TABLE 3: The hesitant fuzzy decision matrix $\mathbf{R}^{3}$ provided by decision maker $D_{3}$.

\begin{tabular}{ccccc}
\hline & $C_{1}$ & $C_{2}$ & $C_{3}$ & $C_{4}$ \\
\hline$A_{1}$ & $\{0.5\}$ & $\{0.4,0.3,0.2\}$ & $\{0.7,0.6\}$ & $\{0.7,0.6,0.5\}$ \\
$A_{2}$ & $\{0.6,0.5\}$ & $\{0.8,0.7\}$ & $\{0.5,0.3,0.2\}$ & $\{0.5,0.4\}$ \\
$A_{3}$ & $\{0.8\}$ & $\{0.5,0.3\}$ & $\{0.9,0.8\}$ & $\{0.9,0.8,0.7\}$ \\
$A_{4}$ & $\{0.9,0.8\}$ & $\{0.7\}$ & $\{0.6\}$ & $\{0.8,0.6\}$ \\
\hline
\end{tabular}

Step 1. The decision makers $D_{k}(k=1,2,3)$ evaluate the software packages $A_{i}(i=1,2,3,4)$ with respect to the criteria $C_{j}(j=1,2,3,4)$ and construct three hesitant fuzzy decision matrices $\mathbf{R}^{k}=\left(h_{i j}^{k}\right)(k=1,2,3)$ (see Tables 1, 2, and 3), where $r_{i j}^{k} \in H$ is a HFE that denotes all of the possible values for the alternative $A_{i}$ regarding the criterion $C_{j}$.

Step 2. Calculate the supports $T\left(r_{i j}^{k}\right)(i=1,2,3,4 ; j=$ $1,2,3,4 ; k=1,2,3)$ for each HFE $r_{i j}^{k}$ from the other HFEs and they are shown in Table 4.

Utilize the HFPA operator to aggregate all of the individual hesitant fuzzy decision matrices $\mathbf{R}^{k}=\left(r_{i j}^{k}\right)_{4 \times 4}(k=1,2,3)$ into the collective hesitant fuzzy decision matrix $\mathbf{R}=\left(r_{i j}\right)_{4 \times 4}$ (see Table 5).

Step 3 (the ratio system). Calculate the scores for $\bigoplus_{j=2}^{4} r_{i j}(i=$ $1,2,3,4)$ and $r_{i 1}(i=1,2,3,4)$ and we have

$$
\begin{array}{ll}
s\left(\bigoplus_{j=2}^{4} r_{1 j}\right)=0.8960, & s\left(r_{11}\right)=0.6137 ; \\
s\left(\bigoplus_{j=2}^{4} r_{2 j}\right)=0.9302, & s\left(r_{21}\right)=0.4848 ;
\end{array}
$$

$$
\begin{aligned}
& s\left(\bigoplus_{j=2}^{4} r_{3 j}\right)=0.9530, \quad s\left(r_{31}\right)=0.7526 ; \\
& s\left(\bigoplus_{j=2}^{4} r_{4 j}\right)=0.9691, \quad s\left(r_{41}\right)=0.8872 .
\end{aligned}
$$

Then, we obtain the overall utility of the $i$ th alternative in terms of the Ratio System, which can be represented by

$$
\begin{aligned}
r_{1}=0.2824, \quad r_{2} & =0.4454, \quad r_{3}=0.2004, \\
r_{4} & =0.0819 .
\end{aligned}
$$

The alternatives are ranked by comparing their overall utility values, and we obtain $A_{2}>A_{1}>A_{3}>A_{4}$ (" $>$ " means "more important than").

Step 4 (the reference point approach). The MORV can be obtained from the collective hesitant fuzzy matirx, which is as follows:

$$
\begin{aligned}
& \varphi_{1}=\{0.5236,0.4856,0.4856,0.4446\} \\
& \varphi_{2}=\{0.7560,0.7289,0.6926,0.6585\} \\
& \varphi_{3}=\{0.8480,0.8282,0.8200,0.8069,0.8059,0.7817 \\
& 0.7807,0.7761,0.7713,0.7702,0.7534,0.7470 \\
&0.7349,0.7213,0.7155,0.7080,0.6785,0.6632\} ; \\
& \varphi_{4}=\{0.8000,0.7707,0.7473,0.7103,0.6808\} .
\end{aligned}
$$

Thereafter, the proposed distance measure is utilized to identify the collective deviation from the MORV for each alternative:

$$
\begin{aligned}
\mathscr{D}_{1}=0.1332, \quad \mathscr{D}_{2}=0.2624, \quad \mathscr{D}_{3}=0.3984, \\
\mathscr{D}_{4}=0.1559 .
\end{aligned}
$$

Then, the alternatives are ranked in descending order of $\mathscr{D}_{i}(i=1,2,3,4)$ and we have $A_{1}>A_{4}>A_{2}>A_{3}$.

Step 5 (the full multiplicative form). The product of the benefit criteria of the $i$ th alternative and the product of cost criteria of the $i$ th alternative are calculated and

$$
\begin{array}{ll}
s\left(U_{1}^{+}\right)=0.1462, & s\left(U_{1}^{-}\right)=0.6137 ; \\
s\left(U_{2}^{+}\right)=0.1911, & s\left(U_{2}^{-}\right)=0.4848 ; \\
s\left(U_{3}^{+}\right)=0.1701, & s\left(U_{3}^{-}\right)=0.7526 ; \\
s\left(U_{4}^{+}\right)=0.3091, & s\left(U_{4}^{-}\right)=0.8872 .
\end{array}
$$

Then,

$$
\begin{aligned}
U_{1}=0.2382, \quad U_{2} & =0.3941, \quad U_{3}=0.2261, \\
U_{4} & =0.3484 .
\end{aligned}
$$

The alternatives are ranked in descending order of $U_{i}$ and we have $A_{2}>A_{4}>A_{1}>A_{3}$. 
TABLE 4: The supports for each HFE from other HFEs.

\begin{tabular}{ccccccccccccc}
\hline & & $C_{1}$ & & & $C_{2}$ & & \multicolumn{2}{c}{$C_{3}$} & & \multicolumn{2}{c}{$C_{4}$} \\
& $\mathrm{DM}_{1}$ & $\mathrm{DM}_{2}$ & $\mathrm{DM}_{3}$ & $\mathrm{DM}_{1}$ & $\mathrm{DM}_{2}$ & $\mathrm{DM}_{3}$ & $\mathrm{DM}_{1}$ & $\mathrm{DM}_{2}$ & $\mathrm{DM}_{3}$ & $\mathrm{DM}_{1}$ & $\mathrm{DM}_{2}$ & $\mathrm{DM}_{3}$ \\
\hline$A_{1}$ & 1.8000 & 1.7000 & 1.7000 & 1.5000 & 1.0500 & 1.4500 & 1.6000 & 1.4000 & 1.4000 & 1.8685 & 1.7370 & 1.8685 \\
$A_{2}$ & 1.7500 & 1.5000 & 1.7500 & 1.2500 & 1.5500 & 1.4000 & 1.4315 & 1.5315 & 1.1630 & 1.6000 & 1.6500 & 1.7500 \\
$A_{3}$ & 1.8000 & 1.6000 & 1.8000 & 1.5500 & 1.7500 & 1.7000 & 1.2130 & 1.5815 & 1.5315 & 1.6500 & 1.3500 & 1.6000 \\
$A_{4}$ & 1.9500 & 1.9500 & 1.9000 & 1.4000 & 1.2500 & 1.5500 & 1.6000 & 1.5000 & 1.7000 & 1.9000 & 1.8000 & 1.9000 \\
\hline
\end{tabular}

TABLE 5: The collective hesitant fuzzy decision matrix $\mathbf{R}$.

\begin{tabular}{|c|c|c|c|c|}
\hline & $C_{1}$ & $\mathrm{C}_{2}$ & $C_{3}$ & $\mathrm{C}_{4}$ \\
\hline$A_{1}$ & $\begin{array}{l}\{0.6894,0.6574,0.6450 \\
0.6302,0.6098,0.6084 \\
0.5774,0.5695,0.5354\}\end{array}$ & $\begin{array}{c}\{0.6450,0.6253,0.6249,0.6074, \\
0.6041,0.5851,0.5102,0.4831 \\
0.4825,0.4583,0.4538,0.4277\}\end{array}$ & $\begin{array}{c}\{0.5275,0.5066,0.4962,0.4813,0.4739 \\
0.4583,0.4470,0.4225\}\end{array}$ & $\begin{array}{c}\{0.6371,0.6100,0.6000,0.5701, \\
0.5686,0.5652,0.5364,0.5208, \\
0.4832\} \\
\end{array}$ \\
\hline$A_{2}$ & $\begin{array}{c}\{0.5236,0.4856,0.4856 \\
0.4446\}\end{array}$ & $\begin{array}{c}\{0.6396,0.6218,0.6057,0.5875 \\
0.5671,0.5487\}\end{array}$ & $\{0.6949,0.6621,0.6482\}$ & $\begin{array}{l}\{0.5501,0.5266,0.5210,0.4959, \\
0.4689,0.4410,0.4345,0.4049\}\end{array}$ \\
\hline$A_{3}$ & $\{0.7726,0.7326\}$ & $\begin{array}{c}\{0.3816,0.3580,0.3480,0.3230 \\
0.3073,0.2808,0.2696,0.2416\}\end{array}$ & $\begin{array}{c}\{0.8480,0.8282,0.8200,0.8069,0.8059 \\
0.7817,0.7807,0.7761,0.7713,0.7702 \\
0.7534,0.7470,0.7349,0.7213,0.7155 \\
0.7080,0.6785,0.6632\}\end{array}$ & $\begin{array}{l}\{0.7905,0.7784,0.7587,0.7447, \\
0.7345,0.7191,0.6950,0.6942, \\
0.6773,0.6764,0.6487,0.6283\}\end{array}$ \\
\hline$A_{4}$ & $\{0.9000,0.8743\}$ & $\{0.7560,0.7289,0.6926,0.6585\}$ & $\{0.6096,0.5861,0.5652\}$ & $\begin{array}{c}\{0.8000,0.7707,0.7473,0.7103, \\
0.6808\}\end{array}$ \\
\hline
\end{tabular}

TABLE 6: Ranking of the alternatives according to MULTIMOORA.

\begin{tabular}{ccccc}
\hline $\begin{array}{c}\text { The ratio } \\
\text { system }\end{array}$ & $\begin{array}{c}\text { The } \\
\text { reference } \\
\text { point }\end{array}$ & $\begin{array}{c}\text { The full } \\
\text { multiplicative } \\
\text { form }\end{array}$ & $\begin{array}{c}\text { MULTIMOORA } \\
\text { (final rank) }\end{array}$ \\
\hline$A_{1}$ & 2 & 1 & 3 & 2 \\
$A_{2}$ & 1 & 3 & 1 & 1 \\
$A_{3}$ & 3 & 4 & 4 & 4 \\
$A_{4}$ & 4 & 2 & 2 & 3 \\
\hline
\end{tabular}

Step 6. According to ranks obtained by the ratio system, the reference point and the Full Multiplicative Form (see Table 6), the Dominance theory is employed to summarize these three ranks provided by respective parts of MULTIMOORA.

By conducting the multiple criteria evaluation process using the MULTIMOORA method, alternative $A_{2}$ is identified as the best choice for the DMs.

Back to the concrete context of the software selection problem, if the information regarding the weights of the DMs and the significant coefficients of the criteria has been obtained, then we can apply Algorithm 21 to support the DMs when making a decision by conducting the following steps.

Step 1. It is the same as Step 1 in Algorithm 20 and hence is omitted here.

Step 2. Calculate the supports $T\left(r_{i j}^{k}\right)(i=1,2,3,4 ; j=$ $1,2,3,4 ; k=1,2,3)$ for each HFE $r_{i j}^{k}$ from the other HFEs and they are shown in Table 7.
Utilize the WGHFPA operator (let $\lambda=2$ ) to aggregate all of the individual hesitant fuzzy decision matrices $\mathbf{R}^{k}=$ $\left(r_{i j}^{k}\right)_{4 \times 4}(k=1,2,3)$ into the collective hesitant fuzzy decision matrix $\mathbf{R}=\left(r_{i j}\right)_{4 \times 4}$ (see Table 8 ).

Step 3 (the ratio system). Calculate the scores for $\bigoplus_{j=2}^{4} \omega_{j} r_{i j}(i=1,2,3,4)$ and $\omega_{1} r_{i 1}(i=1,2,3,4)$ and we have

$$
\begin{aligned}
& s\left(\bigoplus_{j=2}^{4} \omega_{j} r_{1 j}\right)=0.3166, \quad s\left(\omega_{1} r_{11}\right)=0.1670 \text {; } \\
& s\left(\bigoplus_{j=2}^{4} \omega_{j} r_{2 j}\right)=0.3937, \quad s\left(\omega_{1} r_{21}\right)=0.1750 ; \\
& s\left(\bigoplus_{j=2}^{4} \omega_{j} r_{3 j}\right)=0.4218, \quad s\left(\omega_{1} r_{31}\right)=0.3012 \text {; } \\
& s\left(\bigoplus_{j=2}^{4} \omega_{j} r_{4 j}\right)=0.5017, \quad s\left(\omega_{1} r_{41}\right)=0.3319 \text {. }
\end{aligned}
$$

Then, we obtain the overall utility of the ith alternative in terms of the Ratio System, which can be represented by

$$
\begin{aligned}
r_{1}=0.1496, \quad r_{2} & =0.2186, \quad r_{3}=0.1206, \\
r_{4} & =0.1698 .
\end{aligned}
$$

The alternatives are ranked by comparing their overall utility values, and we obtain $A_{2}>A_{4}>A_{1}>A_{3}$ (" $>$ " means "more important than"). 
TABLE 7: The supports for each HFE from other HFEs.

\begin{tabular}{ccccccccccccc}
\hline & & $C_{1}$ & & & $C_{2}$ & & $C_{3}$ & & $C_{4}$ \\
& $\mathrm{DM}_{1}$ & $\mathrm{DM}_{2}$ & $\mathrm{DM}_{3}$ & $\mathrm{DM}_{1}$ & $\mathrm{DM}_{2}$ & $\mathrm{DM}_{3}$ & $\mathrm{DM}_{1}$ & $\mathrm{DM}_{2}$ & $\mathrm{DM}_{3}$ & $\mathrm{DM}_{1}$ & $\mathrm{DM}_{2}$ & $\mathrm{DM}_{3}$ \\
\hline$A_{1}$ & 0.5400 & 0.6000 & 0.6000 & 0.4500 & 0.3700 & 0.5300 & 0.4800 & 0.5000 & 0.5000 & 0.5606 & 0.6080 & 0.6606 \\
$A_{2}$ & 0.5250 & 0.5250 & 0.6250 & 0.3750 & 0.5350 & 0.4750 & 0.4294 & 0.5494 & 0.4020 & 0.4800 & 0.5700 & 0.6100 \\
$A_{3}$ & 0.5400 & 0.5600 & 0.6400 & 0.4650 & 0.6050 & 0.5850 & 0.3639 & 0.5376 & 0.5176 & 0.4950 & 0.4750 & 0.5750 \\
$A_{4}$ & 0.5850 & 0.6850 & 0.6650 & 0.4200 & 0.4300 & 0.5500 & 0.4800 & 0.5200 & 0.6000 & 0.5700 & 0.6300 & 0.6700 \\
\hline
\end{tabular}

TABLE 8: The collective hesitant fuzzy decision matrix $\mathbf{R}$.

\begin{tabular}{|c|c|c|c|c|}
\hline & $C_{1}$ & $\mathrm{C}_{2}$ & $C_{3}$ & $C_{4}$ \\
\hline$A_{1}$ & $\begin{array}{l}\{0.1984,0.1929,0.1851 \\
0.1696,0.1656,0.1598 \\
0.1472,0.1443,0.1401\}\end{array}$ & $\begin{array}{l}\{0.0941,0.0875,0.0819,0.0813 \\
0.0773,0.0744,0.0728,0.0673 \\
0.0646,0.0627,0.0565,0.0511\}\end{array}$ & $\begin{array}{c}\{0.1678,0.1673,0.1539,0.1536,0.1460 \\
0.1454,0.1306,0.1302\}\end{array}$ & $\begin{array}{c}\{0.1518,0.1495,0.1477,0.1345 \\
0.1321,0.1301,0.1216,0.1189 \\
0.1169\}\end{array}$ \\
\hline$A_{2}$ & $\begin{array}{c}\{0.1958,0.1776,0.1734 \\
0.1533\} \\
\end{array}$ & $\begin{array}{c}\{0.1833,0.1757,0.1705,0.1510, \\
0.1422,0.1361\}\end{array}$ & $\{0.1940,0.1782,0.1736\}$ & $\begin{array}{l}\{0.1428,0.1413,0.1339,0.1324 \\
0.1041,0.1033,0.0930,0.0922\}\end{array}$ \\
\hline$A_{3}$ & $\{0.3062,0.2961\}$ & $\begin{array}{l}\{0.0899,0.0897,0.0843,0.0843 \\
0.0566,0.0563,0.0483,0.0482\}\end{array}$ & $\begin{array}{c}\{0.2550,0.2518,0.2467,0.2358,0.2345 \\
0.2324,0.2300,0.2293,0.2281,0.2064 \\
0.2027,0.1968,0.1840,0.1824,0.1799 \\
0.1770,0.1761,0.1747\}\end{array}$ & $\begin{array}{c}\{0.2553,0.2532,0.2323,0.2308 \\
0.2196,0.2172,0.1985,0.1960 \\
0.1941,0.1924,0.1712,0.1694\}\end{array}$ \\
\hline$A_{4}$ & $\{0.3548,0.3089\}$ & $\{0.2960,0.2888,0.2431,0.2381\}$ & $\{0.1905,0.1888,0.1865\}$ & $\begin{array}{c}\{0.2012,0.1809,0.1668,0.1637 \\
0.1402,0.1235\}\end{array}$ \\
\hline
\end{tabular}

Step 4 (the reference point approach). The MORV can be obtained from the collective hesitant fuzzy matrix, which is as follows:

$$
\begin{aligned}
& \varphi_{1}=\{0.1984,0.1929,0.1851,0.1696,0.1656,0.1598,0.1472,0.1443,0.1401\} ; \\
& \varphi_{2}=\{0.2960,0.2888,0.2431,0.2381\} ; \\
& \varphi_{3}=\{0.2550,0.2518,0.2467,0.2358,0.2345,0.2324, \\
& \quad 0.2300,0.2293,0.2281,0.2064,0.2027,0.1968, \\
&\quad 0.1840,0.1824,0.1799,0.1770,0.1761,0.1747\} ; \\
& \varphi_{4}=\{0.2553,0.2532,0.2323,0.2308,0.2196,0.2172, \\
&0.1985,0.1960,0.1941,0.1924,0.1712,0.1694\} .
\end{aligned}
$$

Thereafter, the proposed distance measure is utilized to identify the collective deviation from the MORV for each alternative:

$$
\begin{aligned}
\mathscr{D}_{1}=0.0610, \quad \mathscr{D}_{2} & =0.0449, \quad \mathscr{D}_{3}=0.1411, \\
\mathscr{D}_{4} & =0.1211 .
\end{aligned}
$$

Then, the alternatives are ranked in descending order of $\mathscr{D}_{i}(i=1,2,3,4)$ and we have $A_{2}>A_{1}>A_{4}>A_{3}$.
TABLE 9: Ranking of the alternatives according to MULTIMOORA.

\begin{tabular}{ccccc}
\hline $\begin{array}{c}\text { The ratio } \\
\text { system }\end{array}$ & $\begin{array}{c}\text { The } \\
\text { reference } \\
\text { point }\end{array}$ & $\begin{array}{c}\text { The full } \\
\text { multiplicative } \\
\text { form }\end{array}$ & $\begin{array}{c}\text { MULTIMOORA } \\
\text { (final rank) }\end{array}$ \\
\hline$A_{1}$ & 3 & 2 & 4 & 3 \\
$A_{2}$ & 1 & 1 & 2 & 1 \\
$A_{3}$ & 4 & 4 & 3 & 4 \\
$A_{4}$ & 2 & 3 & 1 & 2 \\
\hline
\end{tabular}

Step 5 (the full multiplicative form). The product of the benefit criteria of the $i$ th alternative and the product of cost criteria of the $i$ th alternative are calculated and

$$
\begin{array}{ll}
s\left(U_{1}^{+}\right)=0.0014, & s\left(U_{1}^{-}\right)=0.1670 ; \\
s\left(U_{2}^{+}\right)=0.0034, & s\left(U_{2}^{-}\right)=0.1750 ; \\
s\left(U_{3}^{+}\right)=0.0031, & s\left(U_{3}^{-}\right)=0.3012 ; \\
s\left(U_{4}^{+}\right)=0.0082, & s\left(U_{4}^{-}\right)=0.3319 .
\end{array}
$$

Then,

$$
\begin{aligned}
U_{1}=0.0087, \quad U_{2} & =0.0196, \quad U_{3}=0.0104, \\
U_{4} & =0.0246 .
\end{aligned}
$$

The alternatives are ranked in descending order of $U_{i}$ and we have $A_{4}>A_{2}>A_{3}>A_{1}$.

Step 6. According to ranks obtained by the ratio system, the reference point and the Full Multiplicative Form (see Table 9), the Dominance theory is employed to summarize these three ranks provided by respective parts of MULTIMOORA. 


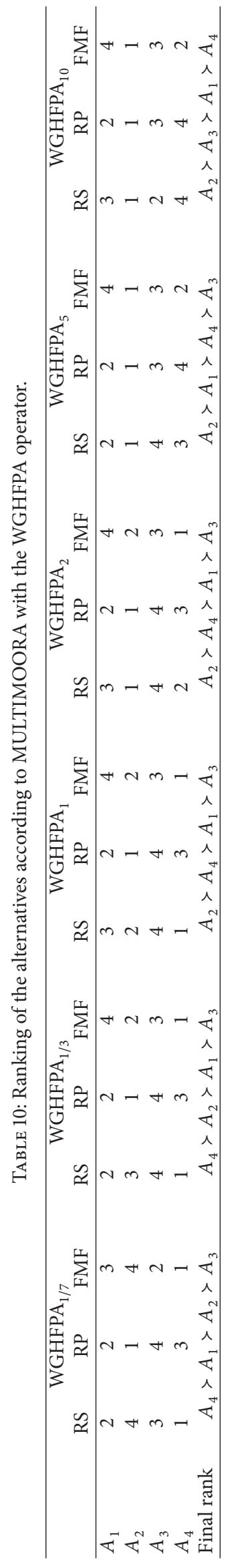


By conducting the multiple criteria evaluation process using the MULTIMOORA method, alternative $A_{4}$ is identified as the best choice for the DMs.

When $\lambda$ varies, we can obtain different results (see Table 10). The DMs can choose the values of $\lambda$ according to their preferences.

In [16], the application of Zhang's method in this example shows that alternative $A_{4}$ is identified as the best choice for the DMs when $\lambda=2$, which is different from the results obtained through the two algorithms proposed in this study. Particularly, the aggregation operator utilized in Algorithm 21 is the same to that used in Approach 1 in [16]. If $\lambda=2$, by comparing the final ranking of the alternatives obtained by our method and Zhang's method, we find out that the rankings obtained by our approach, say $A_{2}>A_{4}>$ $A_{1}>A_{3}$, is totally different from that of Zhang, say $A_{4}>$ $A_{2}>A_{3}>A_{1}$. With the change of the attitudes of the DMs, we can clearly observe that the most desirable alternative will be varied from one to another; this result is therefore more reasonable than that in [16] because the attitudes of the DMs can be effectively reflected while using our method. We provide below a summary of the desirable advantages of our approach over the method of [16].

(i) This study refines the definitions of the score function and distance measure for HFEs and establishes their novel formulas based on PA operator. The proposed score function and distance measure are remarkably different from those proposed in [16] and are investigated highly effective and reasonable because they can alleviate the influence caused by the HFE(s) that is/are of unduly large (or small) deviation. Therefore, the proposed novel definitions will enhance the accuracy of the improved MULTIMOORA method with HFEs and finally lead to precise decision results.

(ii) We propose two algorithms for addressing MCGDM problems to respectively accommodate situations in which the information regarding the weights of the DMs and the significant coefficients of the criteria is unknown or known. That is, our approach is also capable of dealing with situations where the weight and significant coefficient information of the alternatives is unknown or completely known. Furthermore, the improved MULTIMOORA framework proposed in this paper can be flexibly extended to other MCGDM processes, in which the criteria take the forms of high-order fuzzy sets, random variables, fuzzy random variables, and so forth, for obtaining satisfactory decision results. As such, the proposed approaches have a wide applied future.

(iii) We utilize the HFPA and WGHFPA operators in this study to fuse all of the individual hesitant fuzzy decision matrices into the collective hesitant fuzzy decision matrix. Our approach can make the ranking of the alternatives convertible according to the risk attitudes of DMs because the values of the parameters represent the optimistic, pessimistic or neural levels of DMs.

\section{Conclusions}

In this paper, we have defined the novel score function and distance measure for HFEs based on PA operator in order to alleviate the influence of unduly large (or small) deviation during the aggregation process. We further extend the MULTIMOORA method by employing HFEs and propose two algorithms for addressing MCGDM issues. Similar to the crisp MULTIMOORA method, the proposed MULTIMOORA method based on HFEs also consists of the three parts, namely the Ratio System, the Reference Point, and the Full Multiplicative Form, representing different approaches of data aggregation and ranking of alternatives. Therefore, the proposed method could not only provide the means for MCDM related to uncertain assessments, but also facilitate MCGDM with the aid of utilization of information aggregation operators.

A numerical example of software selection demonstrates the possibilities of application of the proposed method. Comparison with other methods further illustrates the reasonability and efficiency of our algorithms. Future studies should focus on development of the MULTIMOORA method in terms of interval-valued hesitant fuzzy sets.

\section{Conflict of Interests}

The author declares that they have no competing interests.

\section{Acknowledgment}

This study was financially supported by the one-hundredtalents scheme of Southwest Jiaotong University of China for Yong Scholars.

\section{References}

[1] L. A. Zadeh, "Fuzzy sets," Information and Computation, vol. 8, pp. 338-353, 1965.

[2] I. B. Turksen, "Interval valued fuzzy sets based on normal forms," Fuzzy Sets and Systems, vol. 20, no. 2, pp. 191-210, 1986.

[3] K. T. Atanassov, "Intuitionistic fuzzy sets," Fuzzy Sets and Systems, vol. 20, no. 1, pp. 87-96, 1986.

[4] K. Atanassov, Intuitionistic Fuzzy Sets: Theory and Applications, Physica, Heidelberg, Germany, 1999.

[5] C.-M. Hwang, M.-S. Yang, W.-L. Hung, and M.-G. Lee, "A similarity measure of intuitionistic fuzzy sets based on the Sugeno integral with its application to pattern recognition," Information Sciences, vol. 189, pp. 93-109, 2012.

[6] J. Li, G. Deng, H. Li, and W. Zeng, "The relationship between similarity measure and entropy of intuitionistic fuzzy sets," Information Sciences, vol. 188, pp. 314-321, 2012.

[7] K. Atanassov and G. Gargov, "Interval valued intuitionistic fuzzy sets," Fuzzy Sets and Systems, vol. 31, no. 3, pp. 343-349, 1989.

[8] R. M. Rodríguez, L. Martínez, and F. Herrera, "Hesitant fuzzy linguistic term sets," in Foundations of Intelligent Systems, pp. 287-295, Springer, Berlin, Germany, 2012.

[9] R. M. Rodríguez, L. Martínez, and F. Herrera, "A group decision making model dealing with comparative linguistic expressions 
based on hesitant fuzzy linguistic term sets," Information Sciences, vol. 241, pp. 28-42, 2013.

[10] O. Castillo and P. Melin, "Optimization of type-2 fuzzy systems based on bio-inspired methods: a concise review," Information Sciences, vol. 205, pp. 1-19, 2012.

[11] D. Dubois and H. Prade, Fuzzy Sets and Systems: Theory and Applications, vol. 144 of Mathematics in Science and Engineering, Academic Press, New York, NY, USA, 1980.

[12] M. H. F. Zarandi, R. Gamasaee, and I. B. Turksen, "A type2 fuzzy c-regression clustering algorithm for Takagi-Sugeno system identification and its application in the steel industry," Information Sciences, vol. 187, pp. 179-203, 2012.

[13] M. Galluzzo and B. Cosenza, "Control of a non-isothermal continuous stirred tank reactor by a feedback-feedforward structure using type-2 fuzzy logic controllers," Information Sciences, vol. 181, no. 17, pp. 3535-3550, 2011.

[14] S. Greenfield, F. Chiclana, R. John, and S. Coupland, "The sampling method of defuzzification for type-2 fuzzy sets: experimental evaluation," Information Sciences, vol. 189, pp. 7792, 2012.

[15] S. Miyamoto, "Multisets and fuzzy multisets," in Soft Computing and Human-Centered Machines, Z.-Q. Liu and S. Miyamoto, Eds., pp. 9-33, Springer, Berlin, Germany, 2000.

[16] Z. M. Zhang, "Hesitant fuzzy power aggregation operators and their application to multiple attribute group decision making," Information Sciences, vol. 234, pp. 150-181, 2013.

[17] V. Torra and Y. Narukawa, "On hesitant fuzzy sets and decision," in Proceedings of the 18th IEEE International Conference on Fuzzy Systems, pp. 1378-1382, Jeju Island, Republic of Korea, August 2009.

[18] V. Torra, "Hesitant fuzzy sets," International Journal of Intelligent Systems, vol. 25, no. 6, pp. 529-539, 2010.

[19] W. Zhou, "On hesitant fuzzy reducible weighted bonferroni mean and its generalized form for multicriteria aggregation," Journal of Applied Mathematics, vol. 2014, Article ID 954520, 10 pages, 2014.

[20] B. Zhu, Z. S. Xu, and M. Xia, "Dual hesitant fuzzy sets," Journal of Applied Mathematics, vol. 2012, Article ID 879629, 13 pages, 2012.

[21] Z. Zhang, "Interval-valued intuitionistic hesitant fuzzy aggregation operators and their application in group decision-making," Journal of Applied Mathematics, vol. 2013, Article ID 670285, 33 pages, 2013.

[22] L. G. Zhou and H. Y. Chen, "A generalization of the power aggregation operators for linguistic environment and its application in group decision making," Knowledge-Based Systems, vol. 26, pp. 216-224, 2012.

[23] L. Zhou, H. Chen, and J. Liu, "Generalized power aggregation operators and their applications in group decision making," Computers and Industrial Engineering, vol. 62, no. 4, pp. 989999, 2012.

[24] R. M. Rodriguez, L. Martinez, and F. Herrera, "Hesitant fuzzy linguistic term sets for decision making," IEEE Transactions on Fuzzy Systems, vol. 20, no. 1, pp. 109-119, 2012.

[25] M. Xia and Z. Xu, "Hesitant fuzzy information aggregation in decision making," International Journal of Approximate Reasoning, vol. 52, no. 3, pp. 395-407, 2011.

[26] D. J. Yu, Y. Y. Wu, and W. Zhou, "Generalized hesitant fuzzy bonferroni mean and its application in multi-criteria group decision making," Journal of Information \& Computational Science, vol. 9, no. 2, pp. 267-274, 2012.
[27] B. Farhadinia, "A novel method of ranking hesitant fuzzy values for multiple attribute decision-making problems," International Journal of Intelligent Systems, vol. 28, no. 8, pp. 752-767, 2013.

[28] Z. Xu and X. Zhang, "Hesitant fuzzy multi-attribute decision making based on TOPSIS with incomplete weight information," Knowledge-Based Systems, vol. 52, pp. 53-64, 2013.

[29] W. K. M. Brauers and E. K. Zavadskas, "The MOORA method and its application to privatization in a transition economy," Control and Cybernetics, vol. 25, no. 2, pp. 445-469, 2006.

[30] W. K. M. Brauers and E. K. Zavadskas, "Project management by multimoora as an instrument for transition economies," Technological and Economic Development of Economy, vol. 16, no. 1, pp. 5-24, 2010.

[31] W. K. Brauers and E. K. Zavadskas, "Robustness of MULTIMOORA: a method for multi-objective optimization," Informatica, vol. 23, no. 1, pp. 1-25, 2012.

[32] W. K. M. Brauers, "Project management for a country with multiple objectives," Czech Economic Review, vol. 6, no. 1, pp. 80-101, 2012.

[33] S. Chakraborty, "Applications of the MOORA method for decision making in manufacturing environment," International Journal of Advanced Manufacturing Technology, vol. 54, no. 912, pp. 1155-1166, 2011.

[34] P. Karande and S. Chakraborty, "Application of multi-objective optimization on the basis of ratio analysis (MOORA) method for materials selection," Materials and Design, vol. 37, pp. 317324, 2012.

[35] W. K. M. Brauers and E. K. Zavadskas, "Multimoora optimization used to decide on a bank loan to buy property," Technological and Economic Development of Economy, vol. 17, no. 1, pp. 174-188, 2011.

[36] A. Baležentis, T. Baležentis, and W. K. M. Brauers, "Personnel selection based on computing with words and fuzzy MULTIMOORA," Expert Systems with Applications, vol. 39, no. 9, pp. 7961-7967, 2012.

[37] T. Baležentis and S. Z. Zeng, "Group multi-criteria decision making based upon interval-valued fuzzy numbers: an extension of the MULTIMOORA method," Expert Systems with Applications, vol. 40, no. 2, pp. 543-550, 2013.

[38] L. Balezentiene, D. Streimikiene, and T. Balezentis, "Fuzzy decision support methodology for sustainable energy crop selection," Renewable and Sustainable Energy Reviews, vol. 17, pp. 83-93, 2013.

[39] D. Streimikiene and T. Balezentis, "Multi-objective ranking of climate change mitigation policies and measures in Lithuania," Renewable and Sustainable Energy Reviews, vol. 18, pp. 144-153, 2013.

[40] D. Streimikiene, T. Balezentis, I. Krisciukaitienè, and A. Balezentis, "Prioritizing sustainable electricity production technologies: MCDM approach," Renewable \& Sustainable Energy Reviews, vol. 16, no. 5, pp. 3302-3311, 2012.

[41] R. R. Yager, “The power average operator," IEEE Transactions on Systems, Man, and Cybernetics Part A:Systems and Humans, vol. 31, no. 6, pp. 724-731, 2001.

[42] V. Torra and Y. Narukawa, Modeling Decisions: Information Fusion and Aggregation Operators, Springer, New York, NY, USA, 2007.

[43] Z. Xu and M. Xia, "Distance and similarity measures for hesitant fuzzy sets," Information Sciences, vol. 181, no. 11, pp. 2128-2138, 2011. 
[44] N. Chen, Z. Xu, and M. Xia, "Correlation coefficients of hesitant fuzzy sets and their applications to clustering analysis," Applied Mathematical Modelling, vol. 37, no. 4, pp. 2197-2211, 2013.

[45] W. K. M. Brauers and R. Ginevičius, "Robustness in regional development studies. The case of Lithuania," Journal of Business Economics and Management, vol. 10, no. 2, pp. 121-140, 2009.

[46] T.-C. Wang and H.-D. Lee, "Developing a fuzzy TOPSIS approach based on subjective weights and objective weights," Expert Systems with Applications, vol. 36, no. 5, pp. 8980-8985, 2009. 


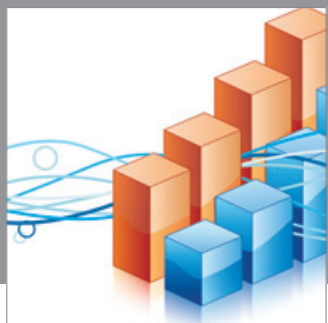

Advances in

Operations Research

mansans

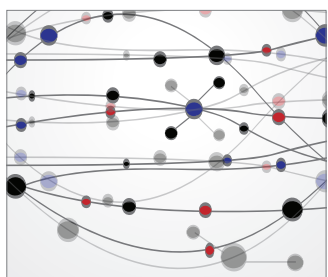

The Scientific World Journal
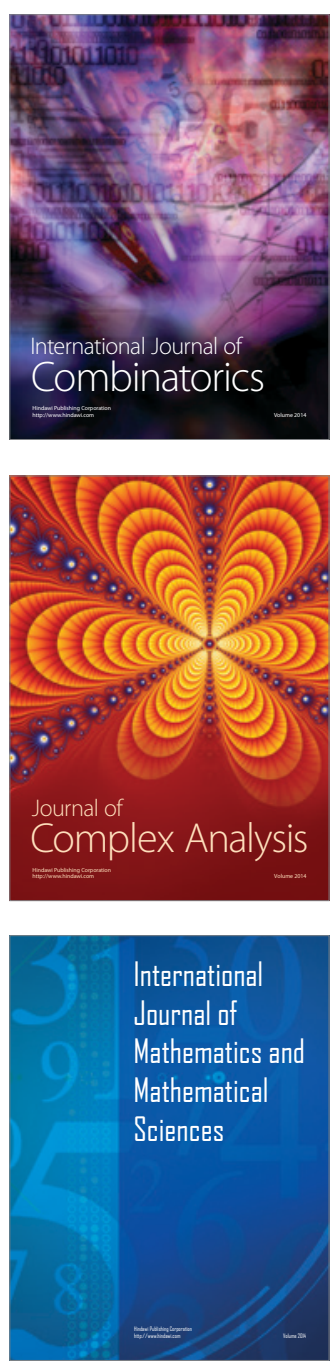
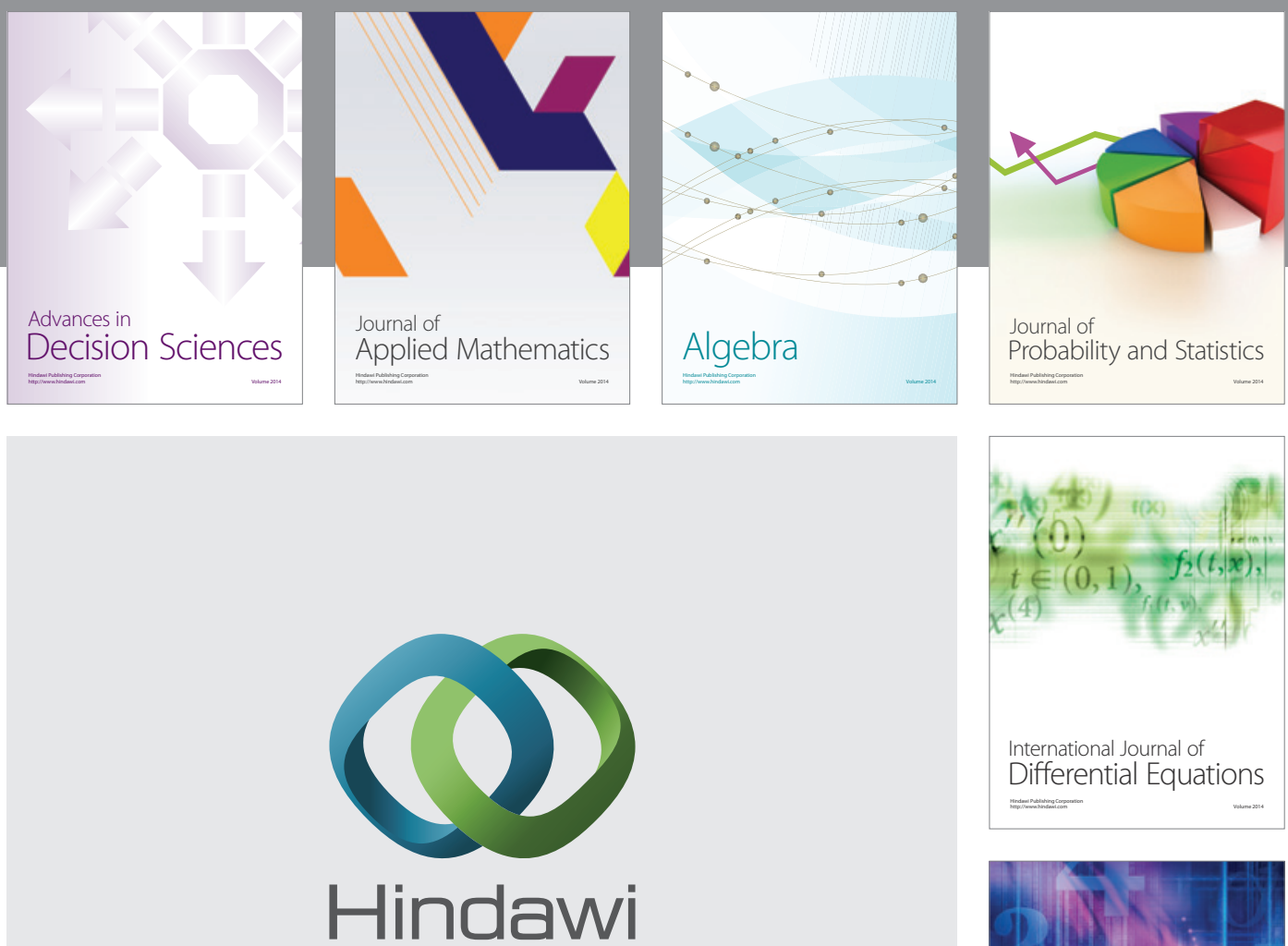

Submit your manuscripts at http://www.hindawi.com
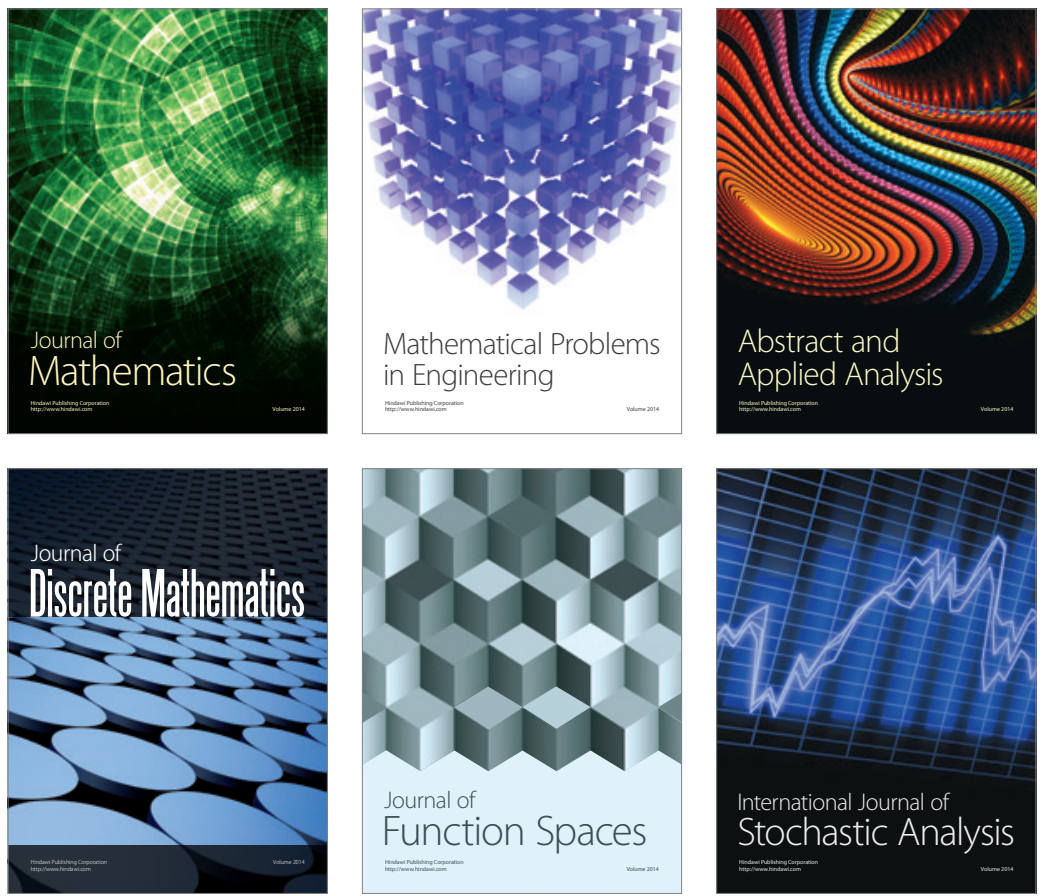

Journal of

Function Spaces

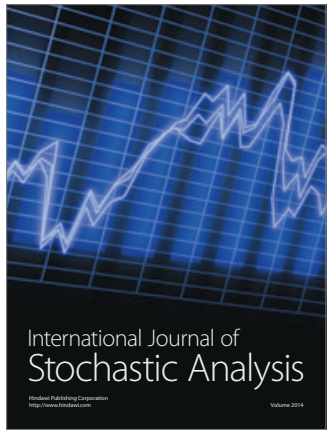

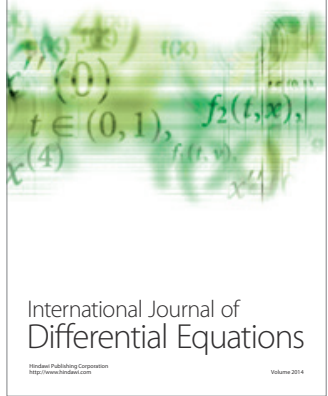
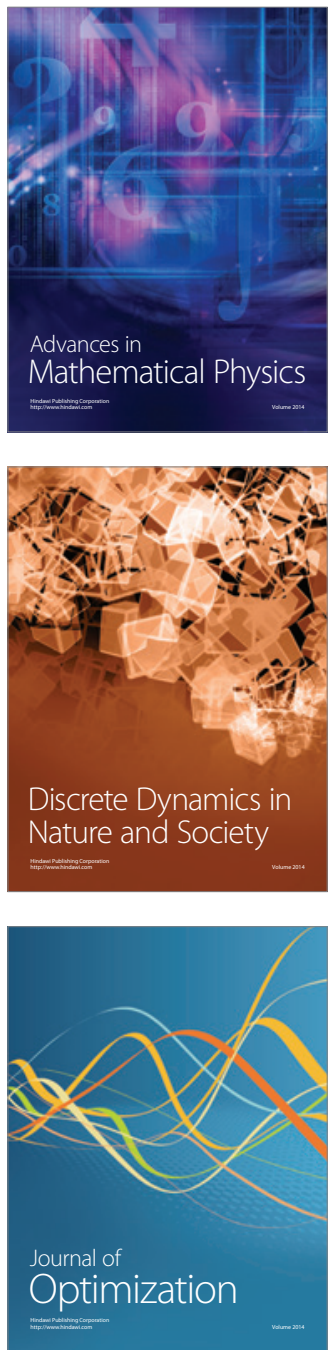